\title{
MEROCOREMIA MONNEI, GEN.N., SP.N. DE COMPSOCERINI \\ (COLEOPTERA, CERAMBYCIDAE, CERAMBYCINAE)
}

\author{
Marinêz Isaac Marques ${ }^{2}$
}

\begin{abstract}
MEROCOREMLA MONNEI, GEN.N., SP.N. OF COMPSOCERINI (COLEOPTERA, Cerambyciddae, Cerambycinae). Are described a new genus, and a new species, including characteres of the wing venation, mouth pieces, proendosternite, metendosternite and ovipositor. This species has a restrict geographical distribution in Espírito Santo and Bahia - Brazil.

KEY WORDS. Cerambycidae, Compsocerini, Merocoremia monnei, new genus. new species
\end{abstract}

O material examinado pertence às seguintes Instituições: Coleção de Entomologia Pe. Jesus Santiago Moure, Departamento de Zoologia, Universidade Federal do Paraná (DZUP); Museu Nacional, Universidade Federal do Rio de Janeiro (MNRJ); Museu de Zoologia, Universidade de São Paulo (MZSP).

A terminologia adotada para a venação alar segue MARINONI \& ALMEIDA (1983); para o metendosternito CROWSON $(1938,1944)$; para a terminália masculina EHARA (1954) e IUGA \& ROSCA (1962) e a masculina e feminina a de LINDROTH \& PALMEN (1970).

\section{Merocoremia, gen.n.}

Espécie tipo: Merocoremia monnei, sp.n.

Cabę̧a (Figs 3-5), na região posterior, levemente constrita, pouco projetada à frente dos olhos e cerca de duas vezes mais longa que larga, na margem anterior do lobo ocular superior. Fronte declive, plana a deprimida entre os tubérculos anteníferos; cerca de duas vezes mais larga que longa, subigual ao comprimento do clípeo. Clípeo subtriangular, a sutura fronto-clipeal angulosa, bem marcada. Área malar bastante reduzida, com cerca de um sexto do diâmetro do lobo ocular inferior; bordo anterior arredondado pouco projetado. Submento transverso, pouco projetado. Suturas gulares curtas, convergentes. Olhos finamente granulados, chanfrados; lobos oculares inferiores quase três vezes mais largos que os lobos superiores (Fig. 5). Lobos oculares inferiores volumosos, bem desenvolvidos e subcontíguos aos alvéolos antenais; ligação entre os lobos subigual à largura do lobo ocular superior e afastada do alvéolo antenal. Tubérculos

1) Contrihuição número 803 do Departamento de Zoologia, Universidade Federal do Paraná.

2) Departamento de Biologia/Zoologia. Instituto de Biociências. Universidade Federal de Mato Grosso. Av. Fernando Corrêa da Costa. 78090-390 Cuiabá. Mato Grosso, Brasil. Bolsista da CAPES. 

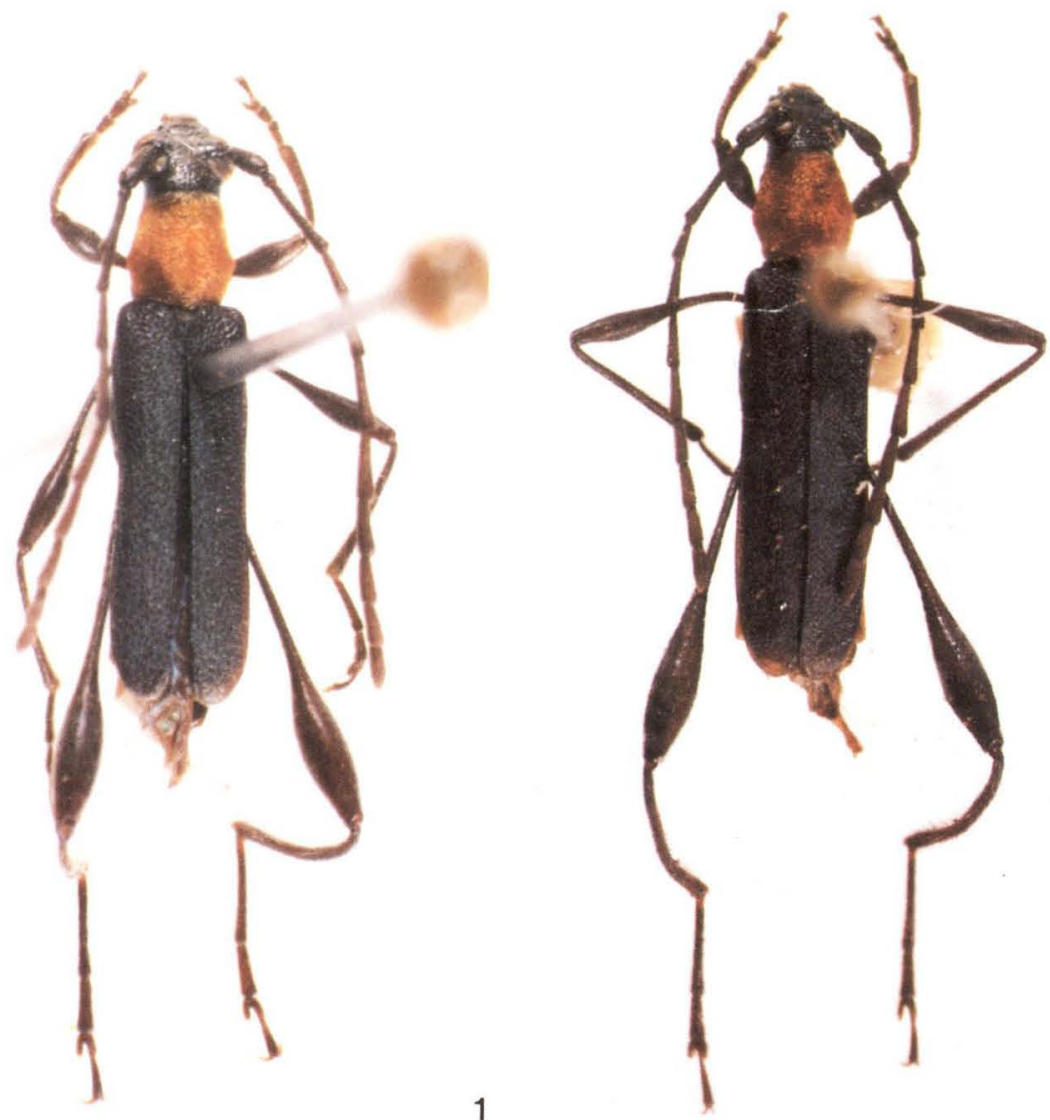

Figs 1-2. (1) Merocoremia monnei, sp.n., holótipo macho, comprimento 5,8 mm; (2) Merocoremia monnei, sp.n., parátipo fềmea, comprimento $8,0 \mathrm{~mm}$.

anteníferos abaulados, apenas salientes; mais distantes entre si que a distância entre os lobos oculares superiores. Labro (Fig. 12) transverso, a borda apical levemente sinuosa, com cerdas alongadas aos lados, mais adensadas e curtas na região mediana. Mandibulas (Figs 7-9) delgadas, a face lateral externa triangular, acuminadas e curvadas no ápice; bordo cortante, ao nível do meio, com dente pouco projetado; franja de pêlos presente até o terço apical. Maxila (Fig. 13): basistipe não fusionado ao dististipe; artículo basal da gálea em forma de anel esclerotinizado desenvolvido. Gálea cilíndrico-capitada, mais alargada em direção ao palpo maxilar e com comprimento subigual ao dos palpos maxilares; pilosidade alongada, mais abundante para a região apical, nesta com pêlos capitados (Fig. 14); base retraída entre o palpígero e lacínia. Esta bem desenvolvida, com franja compacta de cerdas ao longo dos bordos apical e lateral externo; margem interna 

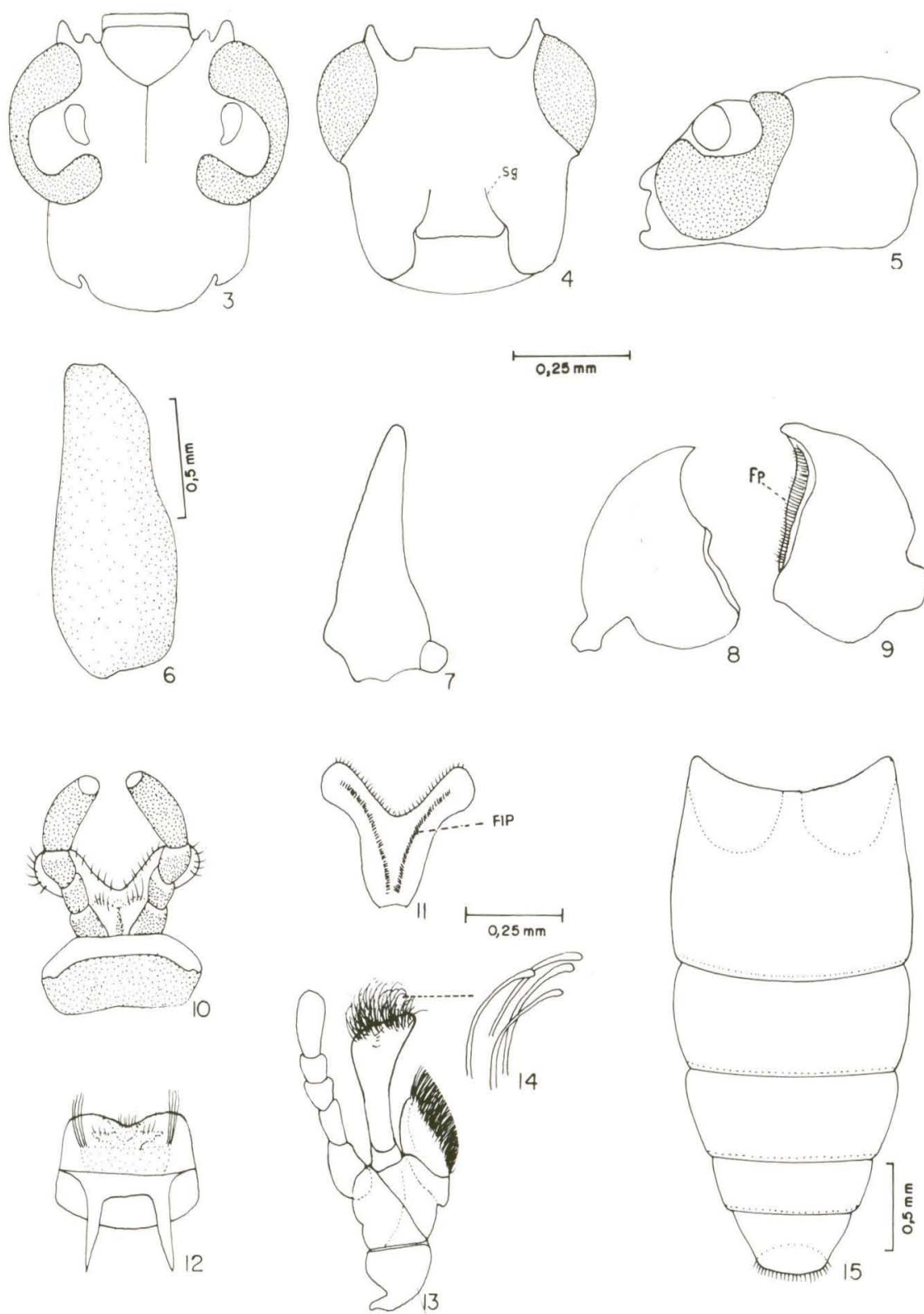

Figs 3-15. Merocoremia monnei, sp.n., (3-5) Cabeça, vista dorsal, ventral e lateral; (6) escapo, macho; (7-9) mandibula, vista lateral, dorsal e ventral; (10) lábio; (11) lígula face interna; (12) labro; (13) maxila; (14) detalhe de pêlos capitados da gálea; (15) abdômen (Flp = Faixa lateral de pêlos; $\mathbf{F} \mathbf{p}=$ franja de pêlos; $\mathbf{S g}=$ Suturas gulares). 
e base esclerotinizadas. Palpos maxilares: artículo basal alongado, pouco mais curto que o apical; segundo e terceiro artículos curtos, cônicos, subiguais em comprimento; artículo apical cilíndrico, apenas atenuado no ápice, mais longo que o comprimento do segundo e terceiro somados. Palpígero bem desenvolvido, afastado da hase da lacínia. Lábio (Fig. 10): mento trapezoidal; lígula membranosa, os lobos laterais bem desenvolvidos; borda apical com chanfro acentuado; face externa com área central pigmentada, mais acentuadamente ao longo do meio, com pilosidade alongada; face interna (Fig. 11) com duas faixas laterais estreitas de pêlos curtos; palpígeros individualizados; palpo com artículo apical cilíndrico, mais longo que o primeiro e segundo somados.

Antenas com onze artículos; revestidas de pilosidade curta, decumbente. No macho (Fig. 1), ultrapassam em 1-2 artículos o ápice elitral; artículos III-X cilíndricos, pouco alongados, os VII-X levemente expandidos para o ápice. Escapo (Fig. 6) subcilíndrico, pouco e gradualmente alargado para o ápice, sem depressão hasal; com comprimento pouco maior que a metade do comprimento do artículo III. Artículo III o mais longo, cerca de duas vezes mais longo que o IV; VIII-X com comprimentos decrescentes e gradualmente intumescidos; o XI pouco mais longo que a metade do III: nas fêmeas (Fig. 2) atingem o ápice elitral ou pouco mais curtas; artículos distais a partir do VIII nítida e progressivamente mais curtos e intumescidos.

Protórax (Fig. 17) com comprimento subigual à maior largura; bordos laterais sinuosos ao nível do meio, projetados em tubérculos algo aguçados, mais evidentes nas fêmeas; sem pontuação sexual; disco plano. Processo prosternal (Fig. 18 ) estreito entre as coxas, os bordos laterais subparalelos, expandidos na região apical. Proendosternito (Fig. 20) membranoso, com aspecto arredondado, pouco desenvolvido, fusionado na linha média; horda lateral com pequenas projeções. Cavidade cotilóide anterior (Fig. 18) pouco angulosa aos lados, aberta posteriormente. Processo mesosternal (Fig. 23) aplanado, cerca de uma vez e meia tão largo quanto a cavidade cotilóide média; com encaixe para a horda anterior do metasterno; bordas laterais subparalelas, a apical entalhada. Cavidade cotilóide média aberta lateralmente. Mesoscuto (Fig. 19) com área estridulatória ovalada. desenvolvida, finamente estriada (50x); apódema interno ausente. Mesendosternito (Fig. 21) retilíneo, obliquamente dirigido para o mesepimero, sem projeções laterais e fusionado à parede do mesepimero. Metepisterno nitidamente estreitado para a borda posterior. Metendosternito (Fig. 22) com pedúnculo estreito, parcialmente fusionado à parede interna do metasterno: braços curtos, fusionados às lâminas; estas curtas e arredondadas; tendões anteriores afastados entre si. as projeções para seu implante reduzidas.

Escutelo (Fig. 19) mais largo que longo, a borda apical arredondada.

Élitros não carenados, subparalelos, os ápices arredondados: na base entre o úmero e o escutelo, não deprimidos, a borda anterior não projetada.

Asa membranosa (Fig. 16) com comprimento aproximadamente igual a três vezes a sua maior largura; loho anal reduzido; Média (M) reduzida a ausente: árculo bem evidente: s-m retilínea; ramo basal da Média Anterior (MA) ausente; 

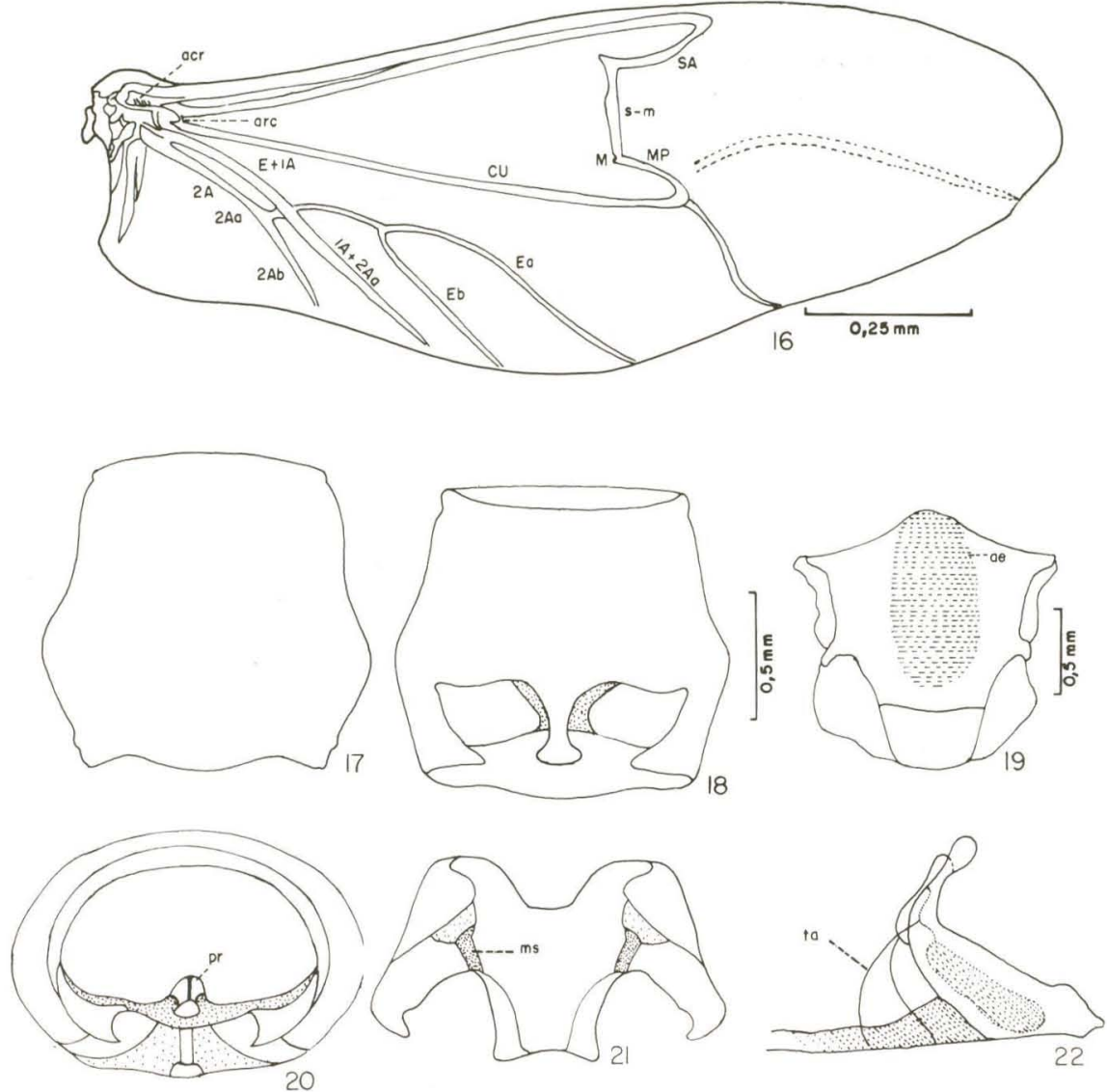
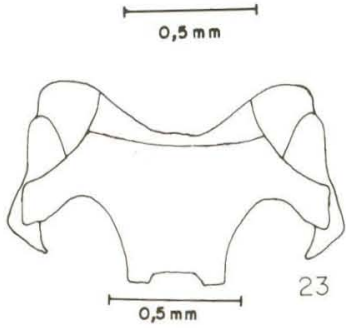

Figs 16-27. Merocoremia monnei, sp.n., (16) Asa membranosa; (17) protórax; (18) prosterno; (19) mesoscuto e escutelo; (20) protórax vista posterior; (21) mesendosternito, vista ventral: (22) metendosternito; (23) mesosterno; $(24,25)$ fêmur e tỉia posteriores; (26) metatarsômero, vista dorsal; (27) empódio $(\mathbf{a c r}=$ área carenada; $\mathbf{a e}=$ área estridulatória $(50 \mathrm{x}) ; \mathbf{a r c}=$ árculo; $\mathbf{C U}=$ Cubital; $\mathbf{E a}=$ ramo a da Empusal: $\mathbf{E b}=$ ramo b da Empusal: $\mathbf{M}=$ Média; $\mathbf{M P}=$ Média Posterior; $\mathbf{m s}=$ mesendosternito; $\mathbf{p r}=$ proendosternito; $\mathbf{S A}=$ Setor Anterior; $\mathbf{s}-\mathbf{m}=$ veia transversa setor - média; $\mathbf{T} \mathbf{a}=$ tendões anteriores; $\mathbf{1 A}=$ Primeira Anal: $\mathbf{2 A}=$ Segunda Anal: $\mathbf{2 A} \mathbf{a}=$ ramo da Segunda Anal; $\mathbf{2} \mathbf{A b}=$ ramo da Segunda Anal). 
distância entre Média Posterior (MP) no ápice e Cubital (CU) cerca de uma vez e meia menor que o comprimento da s-m; transversa $r-s$ ausente; célula da radial aberta: Setor Anterior (SA) alongada; Setor Posterior (SP) ausente; ramos Ea e Eb da Empusal, presentes, a Ea podendo ou não ligar-se à E+1A; Plical (P) ausente: área carenada (acr) na hase da Radial presente.

Pernas (Fig. 1) com comprimentos crescentes, as posteriores cerca de duas vezes e meia mais longas que as anteriores. Fêmures pedunculados e clavados; pedúnculos sem sulcos e carenas; clavas dos fêmures médios alongadas, quase tão Iongas quanto o pedúnculo: pedúnculos posteriores (Fig. 24) quase alcançam o ápice elitral: clava posterior alongada, não ahrupta, subigual ao comprimento do pedúnculo, ultrapassam o ápice elitral pelo seu comprimento. Tíhias subcilíndricas, levemente deprimidas, pouco dilatadas para o ápice; as posteriores (Fig. 25) levemente arqueadas, sem sulcos ou carenas, não dilatadas na metade distal, com cerdas pouco adensadas, o tufo de pêlos ausente. Esporóes tibiais curtos, subiguais. Tarsos com comprimentos crescentes, os posteriores com o dohro do comprimento dos anteriores. Pro- e mesotarsomeros com escovas tarsais compactas, a pilosidade hranco-amarelada. Metatarsômeros I-II (Fig. 26) cilíndricoalongados, mais notavelmente o I. com o dôhro do comprimento do V: escovas tarsais reduzidas a duas fileiras estreitas de pêlos eshranquiçados curtos. com muitos pêlos esparsos ao longo da região mediana: metatarsômero III pouco expandido lateralmente. Empódio (Fig. 27) reduzido, sem cerdas.

Discussão. Apesar da aparente semelhança com Rhopalophora A.- Serville. 1834, este novo gênero é incluído em Compsocerini por apresentar as cavidades cotılóides anterıores angulosias e as médias ahertas lateralmente. Entre os gêneros desta tribo, Merocoremia, gen. n. é hastante próximo de Coremia A. -Serville. 1834, principalmente pelo: 1) padrão das antenas, com os artículos distais progressivamente encurtados e intumescidos, revestidos por pilosidade decumbente; 2) processo mesosternal mais largo que a cavidade cotilóide média; 3) fêmures pedunculados e clavados; 4) metatarsomeros muito alongados; 5 ) padrão da venação alar, principalmente pela ausência da veia Plıcal e a Empusal unida à E + 1A. Distinģue-se de Coremia pela área malar muito reduzida: ausência de tufo de pêlos nas tíhias posteriores; clavas dos fêmures posteriores alongadas e não ahruptas, com comprimento subigual ao do pedúnculo: asa membranosa com presença da veia Emp̣usal be célula da vela Radial aberta: élitros, entre o úmero e o escutelo, não deprimidos, a horda anterior não projetada.

\section{Merocoremia monnei, sp.n.}

Figs $1-36$

Macho (Fig̨. 1). Coloração geral negro; protórax vermelho-alaranjado, revestido por densa pilosidade amarelo-dourada, longa. sedosa e brilhante, com algumas cerdas eretas dorsais e laterais; pernas e antenas negras a castanhas: prosterno com pilosidade amarelo eshranquiçada, alongada, ereta; mesosterno, metasterno e abdômen revestidos por puhescencia serícea, particularmente ahundante nos processos intercoxais. 
Fronte densamente pontuada-corrugada, com abundante pubescência serícea. Clípeo com pontuação fina, adensada, a pubescência pouco aparente. Vértice com pontuação grossa adensada, a superfície sem microescultura, brilhante. Lígula (Fig. 10) com pilosidade pouco alongada e pouco abundante no bordo apical.

Antenas com pubescência amarelada, adensada para os artículos distais, com cerdas acastanhadas e curtas na face ventral dos basais, mais evidentes nos III-IV. Escapo com pontuação fina a média, adensada, a superfície microesculturada, subopaca; pubescência esparsa.

Escutelo com pubescência acastanhada.

Élitros uniforme e densamente corrugado-pontuados, a superfície com evidente microescultura, opaca; pubescência inaparente, com algumas cerdas acastanhadas, eretas, na região basal.

Fêmures com pubescência serícea bem aparente e cerdas esparsas: superfície com microescultura supercial. Tíbias anteriores e médias com abundante pubescência curta, acastanhada e cerdas curtas esparsas. Tarsos com pêlos negro-acastanhados pouco alongados na face dorsal.

Terminália. Macho: oitavo tergito (Fig. 29) transverso, cerca de um terço mais largo que longo, arredondado e pigmentado no bordo apical, com cerdas alongadas, pouco adensadas. Oitavo esternito (Fig. 30) com comprimento subigual à metade do comprimento do oitavo tergito, transverso, bissinuado e com cerdas pouco abundantes no bordo apical; apófise esternal subigual à metade do maior comprimento do esternito. Arco ventral (Fig. 31) com apófise pouco mais longa que a região bifurcada; esta em ângulo agudo; arco dorsal presente, em forma de haste delgada, pigmentada nas regiões laterais. Lobo médio (Fig. 28): lobo dorsal com o bordo apical acuminado, o ventral com ápice bífido; apófises basais cerca de uma vez e meia mais longas que a porção apical; orifício médio alargado, levemente sinuoso; forâmen médio estreitado. Saco interno, ao nível do forâmen médio, com duas peças esclerotinizadas pouco desenvolvidas e fusionadas na base; esta estreita, recortada no bordo apical formando dois pequenos lobos arredondados. Fêmea: oitavo segmento (Figs 35,36) cerca de um terço mais largo que longo, as bordas laterais subparalelas, a apical truncada-arredondada, com cerdas mais abundantes no esternito; apófise esternal quase três vezes mais longa que o esternito. Ovipositor (Figs 33,34) alongado, cerca de duas vêzes mais longo que largo; limite entre as regiões proximal e distal do hemisternito demarcado por constrição acentuada; região distal bífida com lobos diferenciados e com cerdas pouco abundantes; estilos alongados, apicais. Ducto espermatecal forma inúmeros anéis no ponto de ligação com a espermateca; glândula da espermateca pouco alongada, mais curta que a espermateca.

Abdômen. Último urosternito com bordas laterais atenuadas para o ápice, este arredondado (fêmea) a levemente truncado (macho).

Dimensões em milímetros, macho e fêmea, respectivamente. Comprimento total, 5,67 a 7,58 e 5,83 a 8,25; comprimento do protórax, 1,17 a 1,50 e 1,23 a 1,50; maior largura do protórax, 1, 17 a 1,58 e 1,25 a 1,58; comprimento do élitro, 4,08 a 5,50 e 4,25 a 5,92; largura umeral, 1,33 a 1,75 e 1,42 a 1,83 . 


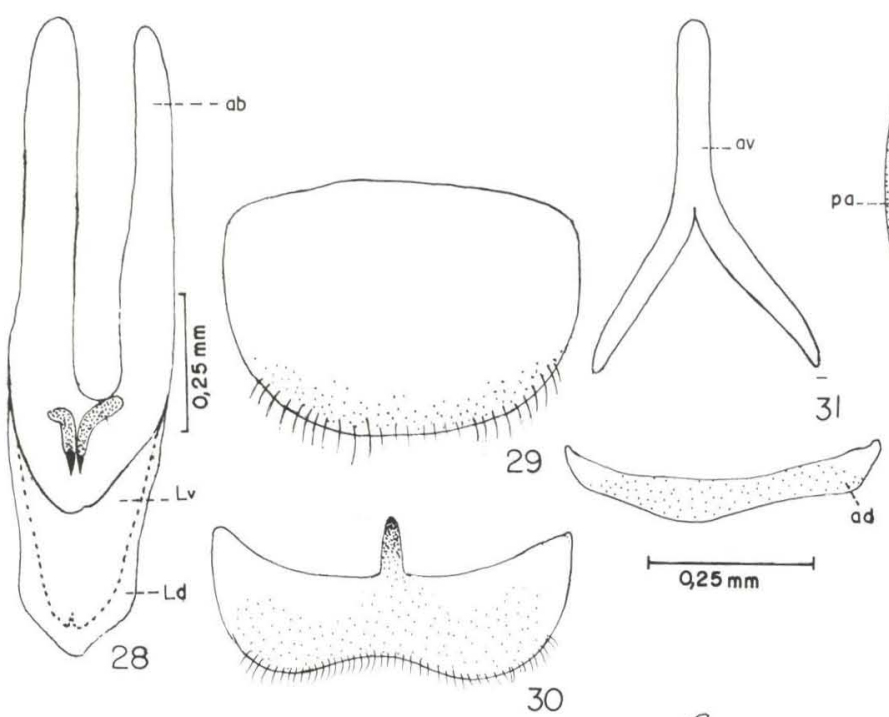

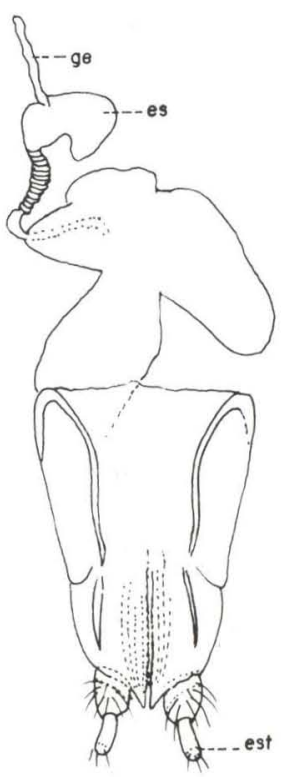

33

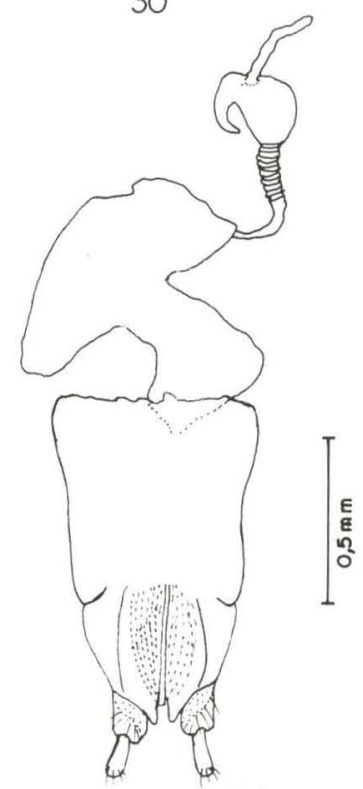

34

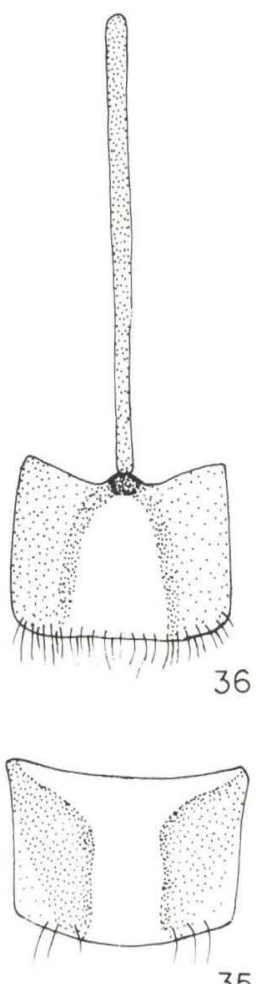

35

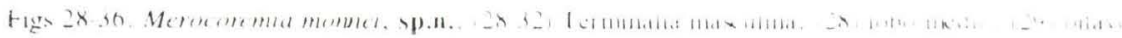
lergito: (30) oitavo esternito: (31) areos dorsal e ventral: (32) Regnena. (33-36) Terminaloa renumina. (33.34) ovipositor (hemisternto IX dorsal e ventral): (35) oitavo tergito: (36) oitavo sesternito $(\mathbf{a b}=$ apofises hasais; $\mathbf{a d}=$ areo dorsal: $\mathbf{a v}=$ arco ventral: $\mathbf{e}=$ espermateca: $\mathbf{m t}=$ estilos: $\mathbf{g e}=\mathrm{gland}$ dula espermatecal: $\mathbf{L d}=$ lobo dorsal: $\mathbf{I} \mathbf{I}$ =lobos laterais: $\mathbf{I} \mathbf{v}=$ lobo ventral: pa=peça anelar: IX = hemisternito 9) 
Holótipo macho (Fig.1). Brasil, Espírito Santo, Baixo Guandu, 26-30.XI.1971, C. Elias leg. (DZUP). Parátipos: BrasiL, Bahia: Condeúba, 2 machos XII. 1975, 1 macho e 1 fềmea I.1976, S.Souza leg. (DZUP). Espírito Santo: Baixo Guandu, 1 macho 5-21.X.1970, 2 machos 8-14.X.1970, 2 machos 15-21.X.1970, C. Elias leg. (DZUP), 1 macho e 1 fêmea X.1971, P.C. Elias leg. (MZSP), 2 fêmeas 8.XI.1971, 2 machos e 1 fềmea 26-30.XI.1971, C. Elias leg. (DZUP), 1 macho e 1 fềmea, X.1976, F.M. Oliveira leg., 5 machos e 5 fềmeas X.1976, E. dos Santos leg. (MNRJ); Colatina, 1 macho 13.XII.1967, C.T. Elias leg., 1 fềmea 16-21.X.1970, C. Elias leg. (DZUP), 2 machos X.1976, O. Oliveira leg., 1 macho X.1976, A. Silva leg. (MNRJ).

Etmologia. Espécie dedicada ao Dr. Miguel A. Monné, do Museu Nacional, Universidade Federal do Rio de Janeiro.

AGRADECIMENTOS. Sinceramente, agradeço à minha orientadora, Dra. Dilma Solange Napp pelo incentivo, apoio e críticas: ao Dr. Miguel A. Monné pelo envio de parte do material estudado; ao Dr. Pe. Jesus S. Moure pelo nome dado ao gênero e ao Dr. Albino M. Sakakibara, pelas fotografias.

\section{REFERÊNCIAS BIBLIOGRÁFICAS}

Crowson, R.A. 1938. The metendosternite in Coleoptera: a comparative study. Trans. ent. Soc. Lond. 87 (17): 397-416. 1944. Further studies on the metendosternite in Coleoptera. Trans, ent. Soc. Lond. 94 (2): 273-310.

EHARA, S. 1954. Comparative anatomy of male genitalia in some Cerambycidae beetles. J. Fac. Hokkaido Univ. 12 (1-2): 61-115.

IUGA, V.G. \& A. RosCA. 1962. La morphologie de l'apex abdominal ches les Cerambycidae (Col.), comparé à celui Hymenoptères. Trav. mus. Hist. "Gr. Antipa" 3: 101-156.

Lindroth, C.H. \& E. PALMEN. 1970. Coleoptera, p.80-88. In: TuxEN, S.L.(ed.) "Taxonomist's glossary of genitalia in insects. Copenhagen, Munksgaard, 359 p.

MARINONI, R.C. \& L.C. ALmEIDA. 1983. Sobre a venação alar em Coccinellidae e Cerambycidae (Coleoptera). Revta bras. Ent. 27 (3/4): 267-275.

Recebido em 30.V.1994; aceito em 14.VII.1994. 